\title{
Uma poética da corporeidade: relações entre destituição subjetiva, o Real do corpo e da cena.
}

LIMA, Carla Andrea

Resumo

Este artigo articula os conceitos de corpo, pulsão e imagem, mobilizados pela teoria psicanalítica, com a noção de acontecimento e Real. O que proponho aqui é uma reflexão que se sustenta numa zona intersticial marcada por experiências-limites no tocante à relação entre subjetividade e corporeidade, para delimitar o que passei a chamar de experiências de borda referentes ao corpo e a assunção do Real no espaço da criação e da cena.

Palavras-chave: imagem corporal, acontecimento; travessia.

\section{Abstract:}

This article articulates the concepts of body image and drive mobilized by psychoanalytic theory, with the notion of event, and Real. Offers an analysis that rests in a interstitial marked by experiences -limits in respect of the relationship between subjectivity and embodiement to delimit what I came to call edge experiences related to the body and the assumption of the Real in the creative process. 
1. O lugar geométrico do olhar constrói corpo

"E o corpo fazia-se planta, e pedra, e lodo, e coisa nenhuma"

Machado de Assis, Memórias póstumas de Braz Cubas.

Assim como as agulhas de tricô que, ao se entrelaçarem umas sobre as outras acabam por construir uma tessitura, a conceituação de corpo, resultante de um modo de olhar e traçar o horizonte a partir do qual um corpo pode "aparecer", acaba por interferir na maneira como damos forma às nossas práticas e investigações artísticas. Dizer que o modo de olhar constitui um horizonte a partir do qual um corpo se faz visível para nós é reconhecer prioritariamente que o modo de olhar emoldura, delimita e faz visível um horizonte de experiências, assim como uma maneira de construir e ouvir o corpo - o do outro e o nosso.

Sabemos de toda construção que ela não se dá separada de um trabalho sobre o vivido e sabemos com a psicanálise que o trabalho sobre o vivido é uma urdidura que inclui vazios, o que permite, no deslizar de uma linha sobre a outra, que o tecido se revele. Donde deduzimos que o tecido formado é composto não só pelas linhas que se entrelaçam - aquilo que faz parte de nosso horizonte de experiências, de nosso plano de visibilidade -, como também pelos espaços vazios - aquilo que da mesma experiência não conseguimos significar, mas que fica, insiste, demarcando um limite, uma impossibilidade, um fora.

Gostaria de frisar que a maneira como construímos os nossos corpos - fruto desse entrelaçamento do que se consolida simbólica e imaginariamente como rede significante e campo de visibilidade com aquilo que se coloca como experiência no limite dos processos de conceituação - interfere no quanto permitimos ao outro construir, isso se nos balizarmos no fato de que os processos de aprendizagem ou de troca de saberes são processos que se caracterizam pela construção do saber na relação consigo e com o outro. Tal como sinaliza Isabelle Launay (2010), as diferentes perspectivas que norteiam o saber em dança, dentre elas uma determinada ideia de corpo, acabam por pautar as relações entre professores, coreógrafos e bailarinos e com isso toda uma vertente de construção e transmissão do saber em dança. A preocupação da autora se direciona para as dinâmicas de poder que são exercidas sobre o corpo e que, por ventura, levam o bailarino a um desconhecimento de seu corpo e de seu desejo. A pesquisadora aponta, nessa relação, para o risco do congelamento de nossas ações 
na medida em que nos alienamos numa engrenagem de identificações que quanto mais nos enreda em seu tecido mais nos faz nos perdermos, posto que, para que esse processo de alienação vigore, um tanto de desconhecimento de si e de sua via desejante deve imperar. Curiosamente, Launay nos propõe testemunhar os gestos e trocas que nos fabricam como uma perspectiva de questionamento dessa engrenagem.

Nesse ponto a pesquisadora dialoga com o trabalho de Hubert Godard, problematizando essa geografia gestual. Para Godard a esfera do gesto não deve ser pensada unicamente em relação ao movimento, mas inserida na vida, levando-se em conta todo seu valor significante e simbólico. Tal valor é considerado a base para a constituição dessa geografia dos gestos que é singular em cada um de nós. Na visão do autor, a "esfera do gesto" deve ser pensada em todo seu alcance simbólico e significante não se restringindo a questões puramente funcionais: "No lugar de pensar o corpo como uma funcionalidade, eu o penso como um universo simbólico de gestos. É esse universo simbólico que vai explicar e forçar a anatomia, e não o inverso" (GODARD, 1994, p. 63-75).

Godard cunha o termo "gestosfera", fundado em diálogo com o conceito de "cinesfera" e ainda com o de "dinamosfera", de Rudolf von Laban. Dessa maneira, com esse termo, propõe uma ampliação do conceito de dinamosfera ao afirmar que a categoria de "gestosfera" nos direciona a interrogarmo-nos sobre os gestos fundadores que nos constituem. Sobre esses gestos é importante frisar que eles se caracterizam por ter um alcance significante em relação ao outro. Dessa forma, dirá Godard, é "bem evidente que é pelo intermédio do outro que uma situação se categoriza como gesto, que é pelo retorno exteroceptivo que se faz a unificação do corpo, que se constitui a imagem do corpo ou o eu exteroceptivo, tal qual fala Lacan" (Ibidem, p. 63- 75). Na visão do autor, são esses gestos fundadores que, vindos do Outro, organizarão o corpo como imagem unificada. Godard sinaliza ainda que eles são muito primários e que se constituem numa relação de objeto: o ser carregado pela mãe, a procura ou recusa do seio, o expulsar ou reter algo de si... Enfim, toda uma esfera gestual que nos primeiros anos de vida se organizam na relação com o outro.

Dessa forma, a constituição do gesto carregará relações com investimentos libidinais, afetivos, presentificados na relação do corpo-sujeito com o outro, assim como com os objetos do mundo. A esses gestos o autor chamou "gestos fundadores". Godard, ao defender o valor simbólico e afetivo dessas marcações como o mais significante para se pensar a esfera do gesto, também acaba por enraizar sua reflexão sobre o corpo nessa zona intersticial corpo/linguagem. 
Trata-se de imaginar, sinaliza o autor, que qualquer coisa se joga metaforicamente, em harmonia com o universo gestual do indivíduo, o que acaba por definir uma zona transicional na qual o gesto, assim como a marcação deste, se constituem na relação com o outro. Algo se joga entre sujeito e outro, algo que se separa deste ao mesmo tempo em que permanece ligado a ele e que faz transporte; como algo que se transmite, que se transporta de um corpo a outro a partir dessa primeira relação de alienação ao outro.

Tendo em vista que pensar o movimento e a corporeidade dançante a partir desses gestos fundadores evocam o contexto bastante complexo da constituição do sujeito, poderíamos supor que testemunhar os gestos e trocas que nos fabricam como uma perspectiva de questionamento dessa engrenagem, tal como sugere Launay, pressupõe o trabalho com as diferentes marcações que foram se sobrepondo sobre esse corpo-sujeito, construindo um modo de olhar e de se posicionar em relação ao desejo do outro e de seu próprio desejo, assim como a forma de pensar e viabilizar experiências corporais a partir desses enovelamentos tecidos entre sujeito-corpo-desejo-Outro.

Para Launay:
A recusa de toda a historicidade na formação do dançarino [a começar pela historicidade de seu corpo], a recusa em lhe oferecer efetivamente uma cultura de ordem mais geral, lhe interdita a possibilidade de saber onde ele está na nossa história, na história dos nossos saberes; a começar pela história das corporeidades, a história da dança e de suas representações coreográficas, história de seu próprio corpo e a própria história de seu desejo de dançar. Então, "fazer um curso" não é mais "estar em curso" (LAUNAY, 2010, p.99).

Tendo isso em conta, para a pesquisadora, "o métier do dançarino pode se revelar alienante se a repetição não pensada do gesto do outro for feita mascarando a história e a geografia dos gestos que o fizeram e o desfizeram" (LAUNAY, 2010, p. 99). Concordamos com Launay quando afirma que, no universo da dança - e poderíamos nos indagar se somente nesse -, certo modo disciplinar parece dominar massivamente a relação do bailarino com seu corpo, em nome de uma utopia fechada e irreal de um corpo normatizado ignorante da historicidade do sujeito, de seu desejo, de sua geografia pulsional singular em prol da imagem de si, alimentada pelo espelho ou por um organicismo confortável.

As problematizações de Launay lançam-nos a questionamentos referentes ao plano de visibilidade dado pelo Outro e como esse plano acaba por permitir ou impedir uma nova possibilidade de vida no vasto campo das práticas de dança. 
Pois se é certo que a autora chama a atenção para problematizarmos que corpo ou ideia de corpo é essa de que nos ocupamos em nossos trabalhos é certo também, dentro do exposto, que torna-se extremamente importante pensar essas questões também pela vertente de um trabalho sobre o negativo (De que corpo não se fala? De que corpo se foge? De que corpo não se quer saber?) que nos permitiria nos perguntarmos sobre os modos de incidência do Real na corporeidade do artista de dança - e também do teatro - assim como na colocação em causa desse na cena sob a vertente do ato e do acontecimento.

Cabe esclarecer com a ajuda de Safatle que:

Contrariamente ao Imaginário (em sua vinculação essencial à imagem) e o Simbólico (em sua vinculação essencial ao significante), a figura lacaniana do Real carece de um operador definido. Em certos momentos da elaboração de Lacan a negatividade do Real aparece vinculada a algo próximo ao conceito de "acontecimento" (événement), desprovido de inscrição simbólica, e em outros, [...], a uma certa noção de irredutibilidade do objeto próxima à noção de "sensível" (SAFATLE, 2005, p. 124).

O que fazer com aquilo que do corpo excede, institui um fora, uma experiência "sensível" que ultrapassa nossa capacidade de entendimento e de organização? Concordamos com Launay que "esse debate remete às capacidades do nosso próprio olhar, às nossas grades de percepção [...] trabalhadas pela nossa língua e informadas pelos nossos hábitos, como a nossa ideologia de corpo, do outro e de si" (LAUNAY, 2010, p. 100). Resta-nos, portanto, ao interrogar esse plano de visibilidade, perguntarmo-nos sobre "o que ele exclui e o que ele permite, sobre quais condições e com quais fins" (LAUNAY, 2010, p. 82).

Aqui devemos pontuar, para a continuidade da reflexão proposta, que problematizamos o "sensível" em consonância com a direção proposta por Vladimir Safatle em seu texto Uma clínica do sensível: a respeito da relação entre destituição subjetiva e o primado do objeto, no qual ele assinala que essa categoria do "sensível" deve ser pensada como materialidade que funciona como "base não-conceitual do pensamento conceitual” (2005, p. 125) e conclui:

Isto não significa que se trata de pensar o sensível como figura de uma positividade que se oferece à intuição imediata. Sensível é aquilo que aparece como operador de resistência ao esquematismo do pensamento categorial. Ele é o que impede que o entendimento hipostasie seu conceito por meio de um procedimento de totalização. Assim, a experiência do sensível deve ser pensada principalmente de maneira negativa, da mesma forma que o Real em Lacan 
só pode ser pensado de maneira negativa como "impossível" que aparece no limite dos processos de conceitualização, e não como a positividade da experiência imediata (via de um realismo do objeto sempre criticada por Lacan) (SAFATLE, 2005, P. 125).

Tendo em vista o exposto por Safatle sobre o "sensível" como um modo de incidência do Real e articulando esse universo conceitual com as questões apontadas por Launay referentes à corporeidade do bailarino, podemos afirmar que a visibilidade atravessa as coisas e as ilumina segundo um regime próprio, mas que esse plano de visibilidade é dependente do ponto a partir do qual olhamos. Dentro dessa perspectiva é importante que coloquemos em trabalho o fato de que esse ponto é dado pelo Outro que totaliza o que, na verdade, é residual e fragmentário.

É em direção a esse residual, ao que Lacan nomeou como resto que pretendemos caminhar. "Resto que, como determinante da divisão do sujeito, o faz decair de seu fantasma e o destitui como sujeito" (Lacan, 2001a, p. 272).

Desse modo, podemos constatar que "a confrontação com aquilo que no sujeito resiste a sua inscrição significante só pode se dar pela vacilação da sua identificação com o lugar fornecido pelo Simbólico" (SAFLATLE, 2005, p. 128) e pelo recorte do fantasma. Tal como aponta Safatle:

\begin{abstract}
o sujeito não é apenas sujeito do significante, mas ele também porta em si mesmo algo da ordem do Real. Daí porque: "O subjetivo é algo que nós encontramos no Real" (Lacan, 1971). De fato, uma desarticulação do poder de formalização do significante, uma vacilação da capacidade de nomeação da palavra aparece como efeito desta confrontação com a negatividade do Real. E é esta lógica que Lacan tenta dar conta por meio da temática da destituição subjetiva. No entanto, ela não exige abandono algum da categoria de sujeito, mas um aprofundamento do que pode ser uma reflexão a respeito das conseqüências do caráter descentrado do sujeito - desse sujeito divido entre o Imaginário do eu, a transcendentalidade do Simbólico e o Real (SAFLATLE, 2005, p. 128).
\end{abstract}

Nesse sentido, Safatle chama a atenção para a articulação entre a categoria de sensível, ancorada pelo conceito lacaniano de Real e a destituição subjetiva que ela opera implicando conjuntamente nessa dinâmica o que Lacan nomeou como travessia do fantasma.

Curiosamente parece ser também em direção a uma travessia que, a meu ver, implicaria também uma destituição subjetiva $^{1}$ o que Launay coloca em operação quando apresenta e problematiza o modo disciplinar que rege a relação do bailarino com seu corpo ao afirmar que "somente aqueles que nós
1.

Isso se tomarmos o conceito de destituição subjetiva como radicalização da problematização lacaniana de sujeito descentrado, o que implica a recusa no aceite de um vínculo ontológico entre sujeito e princípio de identidade. Cf. Safatle, 2005, p. 126. 
poderíamos bem rapidamente chamar 'os felizes da economia libidinal' conseguem, sem muitos problemas, atravessar a provação do domínio ou da renúncia" (LAUNAY, 2010, p. 82). Defendo que a renúncia apontada aqui não é das mais fáceis, posto que pressupõe uma travessia que tem a ver com uma queda de objeto ${ }^{2}$ e com o fading do sujeito. Trata-se aqui de cair do lugar de objeto privilegiado pelo Outro como condição para ter de se haver com sua via desejante singular. Entretanto, "tal confrontação com um desejo vinculado a um objeto que não se submete mais às coordenadas do fantasma impõe uma mudança radical na posição subjetiva, isto se o sujeito for capaz de sustentar o investimento libidinal em um objeto posto nessas condições" (SAFATLE, 2005, p. 143).

Destarte podemos concluir que essa renúncia carrega importantes ligações com uma aposta que precisa ser feita pelo sujeito, uma aposta sem garantias...

Para Lacan, a alienação é condição essencial para a constituição do sujeito. O autor compara esse necessário processo de alienação à tão conhecida escolha entre "a bolsa ou a vida". Uma escolha que ele reconhece ser forçada uma vez que se escolhemos a bolsa perdemos ambas, a vida e a bolsa. Entretanto Lacan salienta que na escolha pela vida, que implica a alienação ao Outro, algo se perde, a libra de carne que nos é tirada para nossa entrada no humano. Trata-se, portanto, sinaliza Lacan, de uma vida que manqueja, "uma vida decepada" (LACAN, 1998 [1964c], p. 201).

É nesse manquejar, nesse tropeço que se configura o sujeito - nesse ponto em que, "entre a causa e o que ela afeta, há sempre claudicação" (LACAN, 1998 [1964a], p. 27), há sempre algo de indefinido, de anti-conceitual. Para Lacan, o inconsciente freudiano "não tem nada a ver com as formas ditas do inconsciente que o precederam, mesmo as que o acompanhavam, mesmo as que o cercam ainda" (LACAN, 1998 [1964a], p. 29). Ele não designa o não consciente, o mais ou menos consciente, nem tampouco "o inconsciente romântico da criação imaginante" (LACAN, 1998 [1964a], p. 29), bem verdade que ele introduz uma outra coisa: é no tropeço, no desfalecimento, na rachadura, numa frase pronunciada em que algo se estatela que se deve procurar o inconsciente. "Ali, alguma outra coisa quer se realizar" (LACAN, 1998 [1964a], p. 30).

O que se produz nessa hiância, nessa fenda, se apresenta como um achado. "Um achado que é, ao mesmo tempo, uma solução - não forçosamente acabada, mas, por mais incompleta que seja tem esse não sei o quê que nos toca" (LACAN, 1998 [1964a], p. 30). Articulado às questões que aqui são postas a trabalho esse "não sei o quê que nos toca" acaba por irromper
$\mathrm{N}$ o caso do bailarino e do ator essa queda diz respeito ao corpo como objeto fantasmático. 
com um sotaque particular de um corpo desconhecido e "esquecido" em relação a qual o sujeito rateia mais ainda assim reconhece um valor único. Ora, esse achado, diz Lacan, uma vez que ele se apresenta, é um "reachado" que está sempre prestes a escapar de novo, instaurando a dimensão da perda. De modo que o espaçamento, a descontinuidade, é marca do Inconsciente, descontinuidade na qual alguma coisa se apresenta como vacilação:

\begin{abstract}
Ora, se essa descontinuidade tem esse caráter absoluto, inaugural, no caminho da descoberta de Freud, será que devemos colocá-la, como foi em seguida a tendência dos analistas sobre o fundo de uma totalidade? Será que o um é anterior à descontinuidade? Penso que não, e tudo que ensinei esses últimos anos tendia a revirar essa exigência de um um fechado miragem à qual se apega a referência ao psiquismo de invólucro, uma espécie de duplo do organismo onde residiria essa falsa unidade. Vocês concordarão comigo em que o um que é introduzido pela experiência do inconsciente é o um da fenda, do traço, da ruptura (LACAN, 1998 [1964a], p. 30).
\end{abstract}

Desse modo, responder pela sua via desejante singular, assim como pensar modos de dança e de atuação menos assujeitados, implica o debruçar sobre esse umbigo, sobre os pontos intraduzíveis do corpo, assim como sobre o radical descentramento do sujeito que trabalha sobre si, descentramento que revela, nesse algo que nos olha e nos convoca pela fresta, que o eu se ancora num desconhecimento radical do si, que no seu mais íntimo lhe fala um outro, - pela via do engano, do tropeço. Nessa fala algo cai e se deixa pegar - a singularidade de seu desejo, desejo por definição inconsciente cujo objeto é inelutavelmente perdido.

\title{
2. A cena, o corpo e o Real
}

A respeito desse horizonte de visibilidade tanto Barthes quanto Lacan pontuam, de formas diferentes, sua relação com a geometria. Lacan problematiza essa questão evocando o cogito, tal como postula Descartes, afirmando que neste "o que visa o eu penso no que ele bascula para o eu sou, é um real" (LACAN, 1998 [1964b], p. 39). O autor sinaliza que o real fica de tal modo de fora que é preciso que Descartes se assegure um Outro que não seja enganador e que, por cima de tudo, possa garantir, só por sua existência, as bases da verdade.

Para Lacan, é exatamente a dimensão de conhecimento vinculado àquilo que é passível de ser objetivado que merece ser questionada. $O$ autor denuncia que essa configuração se sustenta na geometria, tomada como modelo para se pensar a 
consciência reflexiva. É a partir desse lugar - de seu olho-ponto geometral - que o sujeito olha, se reconhece e se representa, alijado do quadro. Entretanto, o autor nos adverte que o lugar do sujeito é diferente do lugar do ponto geometral que define a ótica geométrica, posto que o sujeito em causa não é o da consciência reflexiva, mas o do desejo. Nesse ponto algo se pinta e que de modo algum, salienta Lacan, é simplesmente uma relação construída tomando algo como objeto, mas sim "borboteamento de uma superfície que não é, de antemão, situada para mim em sua distância. Aí está algo que faz intervir o que é elidido na relação geometral - a profundidade do campo, com tudo que ela apresenta de ambíguo, de variável, de não dominado de modo algum por mim" (LACAN, 1998 [1964c], p. 95).

Barthes, seguindo o viés problematizado por Lacan, problematiza essa questão deslocando-a para a cena teatral. Propõe então que pensemos a cena como recorte de um olhar. Recorte que, para o autor, também apresentará uma dialética do desejo, que se presentificará a partir de uma identificação com a Lei do Sentido.

Desse modo, Barthes reivindicará a ligação entre a geometria ${ }^{3}$ e o teatro afirmando que:

O teatro é, na verdade, esta prática que calcula o olhar olhado das coisas: [...]: o palco é essa linha que vem cortar o feixe ótico, desenhando um fim e como que a fronte de seu desenrolar; assim se ergueria contra a música (contra o texto) a representação.

A representação não se define diretamente pela imitação: se abandonarmos noções de "real", de "cópia", de "verossímil", haverá sempre "representação", enquanto alguém (autor, leitor, espectador) dirigir seu olhar para um horizonte e nele recortar a base de um triângulo do que seu olho (ou sua mente) será vértice (BARTHES, 1990, p. 85).

O que parece atrair o olhar de Barthes é concernente exatamente a esse modo de apresentação. Se o teatro é a prática que calcula o olhar olhado das coisas resta-nos indagar sobre o modo de olhar que sustenta a tessitura da cena teatral. O que o texto barthesiano problematiza é o fato de que, na cena posta para o nosso olhar, outro olhar já se deu. O recorte da cena circunscreve um plano para que ali depositemos nosso olhar, que obedece, antes de tudo, à lei do sentido - esta lei que olha, enquadra, focaliza, enuncia. Lei esta que já nos oferece de antemão um plano de visibilidade e nele o que deve ser visto.

Curiosamente é no encontro com a morte representado pelos olhos fechados que Barthes apontará o limite da representação: "Para que a representação seja realmente privada de origem e ultrapasse sua natureza geométrica sem deixar de ser representação, há um enorme preço a pagar: nada menos do
3.

"O teatro e o cinema são, certamente, expressões da geometria (salvo se procederem a alguma pesquisa rara sobre a voz, a esterofonia), mas o discurso literário clássico (legível), abandonando há muito tempo a prosódia, a música, é, também ele, um discurso representativo, pois que recorta trechos para pintá-los: discorrer (teriam dito os clássicos) é 'pintar o quadro que se tem na mente"' (BARTHES, 1990, p. 86).A questão de Barthes esbarra na questão da legibilidade da cena e sua identificação com o quadro, ao realizar "a coincidência do recorte visual com o recorte das ideias" (BARTHES, 1999, p. 86). Da cena o autor critica a dinâmica do recorte identificado com a legibilidade da figura como se a cena devesse ser posta ao espectador como uma comida (quando se diz a mesa está posta) para assimilação e entendimento. 
que a morte" (BARTHES, 1990, p. 91). A morte aqui se caracteriza como o encontro com a perda, com o furo (o olho do morto) que acaba por fazer vacilar o recorte que se quer inteiro, sem falhas revelando ali a presença de uma concretude impossível e desconcertante posto que nos impede de hipostasiar o sentido pela via da totalização.

Mortífero é o olhar da medusa porque nele não podemos identificar o nosso. O olhar da medusa não espelha o nosso, mas devolve nossa impossibilidade de olhar. Nesse olhar que petrifica há algo que não se pode - nem se quer ver por preço algum. Podemos pensar que o que marca o limite da representação é o ponto em que o sujeito não pode depositar na cena seu olhar porque nessa cena ele está incluído, não por identificação, mas por incapacidade de se reconhecer separado da coisa vista.

O que o olhar do morto nos mostra é o descentramento do sujeito, que aponta para a própria esquize do sujeito, impedindo a delimitação de um dentro/fora e a restrição do olhar à esfera do visível. Nessa cena o sujeito é um incluído/excluído, assim como o olhar do morto lhe é estranho/entranho.

Imagine então o olhar do morto, imagine a impossibilidade de nele ancorar o seu olhar, imagine que este, por ser sem apoio, nos olha como uma obra de perda, pois que produz atravessamento. Dessa forma, o que nos olha, vazando o recorte (e tornando-o vazado) acaba retornando no que acreditamos apenas ver. Imagine esse retorno, sua inquietante estranheza.

É sobre essa inquietante estranheza presente na inelutável modalidade do visível que Didi-Huberman se debruçará buscando pensar o estatuto do visível sem sujeitá-lo à esfera da discursividade. Sujeição esta que acabaria por nos apresentar um olhar sem sujeito. O que está em questão aqui é o próprio sujeito que sustenta esse olhar

\footnotetext{
Ora, o objeto, o sujeito e o ato de ver jamais se detêm no que é visível, tal como o faria um termo discernível e adequadamente nomeável. [...] O ato de ver não é o ato de uma máquina de perceber o real enquanto composto de evidências tautológicas. [...] Dar a ver é sempre inquietar o ver, em seu ato, em seu sujeito. Ver é sempre uma operação de sujeito, portanto uma operação fendida, inquieta, agitada, aberta. (DIDI-HUBERMAN, 1998, p. 77).
}

Para Didi-Huberman, uma coisa a ver, por mais exposta, por mais neutra torna-se inelutável quando uma perda a suporta e desse ponto nos olha, nos concerne, nos persegue, tal qual uma peste. Assim, a modalidade do visível se torna inelutável quando ver é sentir que algo nos escapa, quando ver é perder. 
3. A queda do corpo no corpo: opacidade

e modos de incidência do Real

O homem está capturado pela imagem de seu corpo. Este ponto explica muitas coisas e, em primeiro lugar, o privilégio que tem a dita imagem para ele. Seu mundo, se é que esta palavra tem algum sentido, seu Umwelt, o que o rodeia, ele o corpo-reifica, o faz coisa à imagem de seu corpo. Não tem a menor ideia, certamente, do que acontece neste corpo.

Lacan

Sabemos que a experiência do espelho tem um caráter primordial na teoria psicanalítica, isso se a entendermos, mais do que como uma fase do desenvolvimento da criança, como um modelo que atravessa toda a vida do sujeito, representando a relação libidinal essencial que este tem com sua imagem corporal. Lacan atribui à imagem um papel fundador tanto na formação do eu quanto na matriz simbólica do sujeito, definindo a identificação, sob essa perspectiva, como "a transformação produzida no sujeito quando assume uma imagem" (LACAN, 1998 [1949], p. 97). Para Lacan, a corporeidade é fundamentalmente uma experiência vinculada à imagem do corpo o que pressupõe que a ideia de si como um corpo será feita a partir da identificação do eu com sua imagem.

Convém examinar que, para Lacan, a imagem não é uma "representação passiva que teria apenas a função de informação de um dado ao qual ela se assemelha" (SAFATLE, 2006, p. 78), mas uma Gestalt, uma forma que tem pregnância. Sabemos que a Gestalt em jogo no estádio do espelho é a forma do corpo. Forma essa que possibilita um princípio global de organização:

\footnotetext{
De um lado, a imagem fornece aquilo que a percepção não pode nos dar, ou seja, uma apreensão global dos objetos. [...] de outro, esse princípio não diz respeito apenas à apreensão imaginativa de objetos particulares, pois a imagem, ao configurar objetos simultâneos no espaço, organiza o campo do visível, ou melhor, organiza o visível como campo. Ela organiza o espaço no qual um objeto pode aparecer (SAFATLE, 2006, p. 78).
}

Para Lacan, o infans, com seu corp's morcelé, se antecipa numa unidade a partir da imagem representada pelo olhar do outro, no qual ele vai se alienar virtualmente. Isto porque o eu se constitui, primeiramente, numa relação de exterioridade, mais especificamente a partir de uma identificação do infans a uma imagem que lhe é exterior e que não coincide com o que ele experimenta como um corpo. Desse modo, o estádio 
do espelho, ao mesmo tempo em que possibilita uma primeira "matriz simbólica onde o eu [je] se precipita em sua forma primordial" (LACAN, 1998 [1949], p. 97), assinala o desconhecimento e a alienação deste. Sob esse viés para o homem, o corpo não é algo evidente, não é um dado imediato da consciência. $O$ que faz Camille Demoulié afirmar, em articulação com Lacan, que "construímos, mais ou menos seguindo a ordem dos outros, o que chamamos de nosso corpo, de forma que poderíamos pensar que nada é mais impróprio que o nosso pretenso 'corpo próprio'” (DEMOULIÉ, 2001, p. 2).

Entretanto, é o mesmo Lacan que sinaliza que esta captura do sujeito pela imagem nunca será integral, posto que teremos, como resultante dessa operação, um resto não-especularizável. Algo do corpo permanece como resto e, portanto, inacessível à apreensão por parte do sujeito via imagem. Pensado por esse viés, o corpo se constitui como uma realidade instável. Mantém-se uma relação tumultuada entre o invisível que nos constitui e o plano de visibilidade que nos permite reconhecermo-nos como um corpo.

Se, tal como salienta Safatle, os objetos parciais são objetos que o "sujeito deve perder a fim de desenvolver processos de auto referência mediante a formação do eu" (2006, p. 205) defendo, analogamente, que a incidência sensível de um corps morcelé também deve ser "perdida" a fim de que a constituição de um corpo, ou melhor, da ideia de si como corpo possa advir.

Interrogo-me então sobre isso que cai e que nomeio "queda do corpo no corpo". Pergunto sobre esses pontos cegos, pontos do corpo que a imagem denega. Defendo que esses pontos estariam restritos a um "fora" do corpo exatamente por serem nucleares a ele. Atento-me então sobre isso estranho/ entranho ao corpo, sobre isso que, exilado da imagem, não obstante a constitui.

Lacan propõe que pensemos as primeiras relações objetais como relações que se fazem nas bordas do Outro, nesse caso o outro materno, bordas que estabelecem uma zona de confusionamento entre corpo da criança e corpo da mãe. O autor sublinhará a topologia de borda própria ao objeto a (objetos pulsionais que, no corpo, definem-se por estarem, de alguma forma, fora do corpo), já que ele marca o espaço de quiasma entre sujeito e Outro, entre dentro e fora.

A psicanálise nos abre, portanto, para essa característica dos objetos pulsionais, o de serem objetos estranhos e entranhos ao corpo, de forma que poderíamos nos interrogar se o corpo também não carrega esse caráter extimo. Importante salientar que o termo extimidade, tal como o propõe Lacan, se constrói sobre o de intimidade não sendo simplesmente seu 
oposto, o extimo é precisamente o íntimo, o mais íntimo. "Esta palavra indica sem embargo, que o mais íntimo está no exterior, que é como um corpo estranho" (MILLER, 2004, p. 14).

Exilado do corpo, esse corpo estranho habita-o do exterior, o interroga em seu fora, em sua perda, constituindo aquilo que ele tem de mais singular. O resultado é a invasão de outro corpo, um corpo estrangeiro e estranhado.

O que nos interessa é, a partir disso, frisar um ponto bastante específico da articulação lacaniana no que diz respeito à imagem corporal em seu estatuto de objeto fantasmático. Lacan, por volta dos anos 6o, fará um retorno ao problema da imagem do corpo próprio construindo "a metáfora do corpo especular como vestimenta (habillage) do objeto a" (SAFATLE, 2006, p, 210). Dessa forma, o que resta não-especularizável na imagem corporal, aquilo que escapa ao sujeito, seus pontos cegos, seria ao mesmo tempo o que a sustenta. Tomemos Safatle: "no fundo da imagem especular, há este objeto que escapa ao sujeito, ao mesmo tempo em que o constitui" (SAFATLE, 2006, p. 210). Sobre esse "algo que escapa" vale salientar que Lacan nos alerta para o fato de que não é que ele escape pura e simplesmente, mas que esse algo intervém com uma incidência cujo modo de perturbação é a angústia e o advento do estranho (LACAN, 2005 [1963a], p. 98).

Para Safatle, devido ao primado da imagem na experiência do corpo, perde-se acesso à objetalidade do corpo e com ela à sua opacidade. Opacidade aos procedimentos de autorreflexão que acabam por apontar para o estatuto problemático do corpo. O que significa também que "a dissolução da imagem do corpo pode aparecer como desvelamento do objeto a" (SAFATLE, 2006, p. 210). Dessa forma estamos diante de um corpo que, atravessado pela linguagem, não deixa de se situar num lugar de exílio, ou seja, o Real do corpo.

Cabe aqui nos atentarmos para o movimento lacaniano de aproximação da dimensão do objeto $a$, não submetida à imagem, ao conceito de carne. A carne, marca a insistência do informe e indica, sobretudo, o que há de impessoal no sujeito (Cf. SAFATLE, 2006). Tal como sinaliza o filósofo Camille Dumoulié: "Existimos dentro de um corpo singular, com todo o movimento de expropriação do verbo ex-istir" (2011, p. 1).

Dessa forma poderíamos pensar que o ator-bailarino, ao trabalhar sobre si, opera nessa travessia seu próprio desaparecimento. Quilici salienta que desviar-se desse sistema que nos prende numa espécie de fantasmagoria exigiria o lidar com o que ele chama de "ansiedades relativas á desintegração de nossa imagem e à morte" (2006, p. 4) como a nos alertar para o fato de que o trabalho sobre a corporeidade carrega em seu 
horizonte algo da ausência, do informe, da morte. E também tangencia um espaço de travessia que viemos aproximando à travessia do fantasma e sua decorrente destituição subjetiva.

Para Coutinho Jorge (2010, p. 217), "toda obra de arte parece ter um compromisso com a função do despertar", tomado por ele como um descentramento do homem de si mesmo, "um despertar para o mais além do sentido narcísico e, portanto, imaginário"(2010, p. 204), um despertar para o Real. O autor sinaliza ainda que o despertar remete o sujeito a um tempo perdido, em que "ele ainda não tinha um nome, não se diferenciava por nenhum traço particular, antes se confundia com a vida em qualquer de suas emergências mais brutas" (Ibidem, p. 221).

Resta ao ator-bailarino, portanto, a busca por criar um si-corpo que não tenha ancoragem na imagem, um si-corpo sem apoio. Desse ponto opaco - ponto de perda - o corpo nos olha até o âmago. Talvez ter um corpo seja sentir que algo do corpo inelutavelmente nos escapa. Dentro dessa perspectiva a articulação de Quilici o aproxima das proposições de Safatle, na medida em que reconhece a impossibilidade dessa presença sem um trabalho sobre o ausente, sobre aquilo que resta - e sempre restará -, obliterado, como experiência de um sensível que tangencia um enovelamento singular que pressupõe o não-nascido, o devir, o espaçamento.

Encerro com as palavras de Lucien Israël:

A fantasia na qual o sujeito está encarcerado, afogado, mergulhado, emparedado, nos serve de crivo para recortar, na realidade do mundo, as constelações que nos convém. Mas são constelações escolhidas sobre o crivo da fantasia. Em outras palavras, pelo tempo que o sujeito estiver prisioneiro da fantasia, o outro do encontro amoroso, e pouco importa seu sexo, vai ser um outro projetivo, um outro conforme o fabriquemos em nossas representações primordiais. [...] Mas se a fantasia for aberta, desencapsulada, [..], nesse momento estaremos em presença de um sujeito desejante que pode escolher um outro radicalmente diferente dele, sem nenhuma relação com ele, um outro que constitui a abertura em direção a uma nova aventura, em direção a uma vida nova que não era previsível, nem programável, nem representável, e que, no limite, não era sequer possível (ISRAËL apud COUTINHO JORGE, 2010, p. 244). 
DUMOULIÉ, Camille. "O timbre intraduzivel do corpo: Artaud, Merlau-Ponty, Lacan". Revue Silène Centre de Recherches em littérature et poétique comparées de Paris Oues-Nanterre-La Defense, 2010. Disponível em: http:// www.revuesilene. comf/ index.php?sp=comm\&comm_id=59.

GODARD, Hubert. « Le geste manquant ». Entretien réalisé par Daniel Dobbels et Claude Rabant. Etats de corps. (Revue de Psychanalyse), $n^{\circ}$ 5. France : Éres,1994. p.63-75.

LACAN, Jacques. "Do sujeito enfim em questão". In: Escritos. Rio de Janeiro: Jorge Zahar, 1998.

LACAN, Jacques. "O estádio do espelho como formador da função do eu". In: Escritos. Rio de Janeiro: Jorge Zahar, 1998.

LACAN, Jacques. O seminário, livro X: a angústia. Rio de Janeiro: Jorge Zahar Editores, 2005 [1963a].

LAUNAY, Isabelle. "O dom do gesto" In: GREINER, Christine e AMORIM, Claudia (orgs.). Leituras do corpo. São Paulo: Annablume, 2010.

QUILICI, Cassiano. "A experiência da não forma e o trabalho do ator", Revista territórios e fronteiras da cena. São Paulo. Edição 1, ano 3, 2006.

SAFATLE, Vladimir. Uma clínica do sensivel: a relação entre destituição subjetiva e primado do objeto. Revista Interações, v. X, no 19, p. 123 - 150, Jan-Jul, 2005. SAFATLE, Vladimir. A paixão do negativo: Lacan e a dialética. São Paulo: Editora UNESP, 2006. 